\title{
Binding Mode Prediction of 5-Hydroxytryptamine 2C Receptor Ligands by Homology Modeling and Molecular Docking Analysis
}

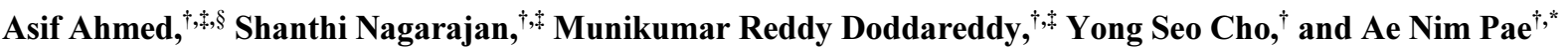 \\ ${ }^{\dagger}$ Neuro-medicine centre, Life Sciences Division, Korea Institute of Science and Technology, Seoul 130-650, Korea \\ ${ }^{*}$ E-mail: anpae@kist.re.kr \\ ${ }^{\ddagger}$ School of Science, Korea University of Science and Technology, Daejeon 305-333, Korea \\ ${ }^{\S}$ Biotechnology and Genetic Engineering Discipline, Khulna University, Khulna-9208, Bangladesh \\ Received February 8, 2011, Accepted April 4, 2011
}

\begin{abstract}
Serotonin or 5-hydroxytryptamine subtype $2 \mathrm{C}\left(5-\mathrm{HT}_{2} \mathrm{C}\right)$ receptor belongs to class A amine subfamily of Gprotein-coupled receptor (GPCR) super family and its ligands has therapeutic promise as anti-depressant and -obesity agents. So far, bovine rhodopsin from class A opsin subfamily was the mostly used X-ray crystal template to model this receptor. Here, we explained homology model using beta 2 adrenergic receptor $(\beta 2 \mathrm{AR})$, the model was energetically minimized and validated by flexible ligand docking with known agonists and antagonists. In the active site Asp134, Ser138 of transmembrane 3 (TM3), Arg195 of extracellular loop 2 (ECL2) and Tyr358 of TM7 were found as important residues to interact with agonists. In addition to these, V208 of ECL2 and N351 of TM7 was found to interact with antagonists. Several conserved residues including Trp324, Phe327 and Phe328 were also found to contribute hydrophobic interaction. The predicted ligand binding mode is in good agreement with published mutagenesis and homology model data. This new template derived homology model can be useful for further virtual screening based lead identification.
\end{abstract}

Key Words : 5- $\mathrm{HT}_{2 \mathrm{C}}$ receptor, Homology modeling, G-protein-coupled receptor, Molecular docking

\section{Introduction}

GPCRs comprised of largest integral membrane protein family in the human genome and have over one thousand members. ${ }^{1,2}$ The ligands for the GPCRs also vary a lot; ions, organic odorants, amines, peptides, proteins, lipids, nucleotides, and even photons are able to mediate their message through these proteins. Serotonin or 5-hydroxytryptamine (5-HT) is a major neurotransmitter in animals, both vertebrates and invertebrates, which regulates many important physiological processes. ${ }^{3}$ 5-HT receptors belong to amine subfamily of class A GPCR and comprised of seven members; $5-\mathrm{HT}_{1}$ to $5-\mathrm{HT}_{7}$, except $5-\mathrm{HT}_{3}$ which is an ion channel, ${ }^{4}$ these receptors binds with endogenous neurotransmitter serotonin (5-hydroxtryptamine) ${ }^{5}$ More than fourteen 5-HT receptor subtypes have been identified, with splice variants and isoforms created by mRNA editing. ${ }^{6} 5-\mathrm{HT}_{2}$ receptors have three major subtypes; $5-\mathrm{HT}_{2 \mathrm{~A}}, 5-\mathrm{HT}_{2 \mathrm{~B}}$ and $5-\mathrm{HT}_{2 \mathrm{C}}$. The subtypes are related in their molecular structure, amino acid sequence and signaling properties. ${ }^{7}$

The $5-\mathrm{HT}_{2 \mathrm{~A}}$ receptor and the $5-\mathrm{HT}_{2 \mathrm{C}}$ receptor are closely related members of the GPCR activated by endogenious ligand serotonin that share very similar pharmacological profiles and cellular signaling pathways. The $5-\mathrm{HT}_{2 \mathrm{C}}$ receptor is abundant in CNS. ${ }^{8}$ It is mostly populated in epithelial cells of the choroid plexus, and also occurs in many brain regions, including the olfactory nuclei, the olfactory bulb, the substantia nigra, the cerebral cortex, the hippocampus and the hypothalamus, as well as in the spinal cord. $.^{9-11} 5-\mathrm{HT}_{2 \mathrm{C}}$ receptor is the only $7 \mathrm{TM}$ receptor that is known to undergo post-transcriptional process of RNA editing; which generates 14 unique receptor isoforms of the $5-\mathrm{HT}_{2 \mathrm{C}}$ that differ in three amino acids in the second intracellular loop. ${ }^{6,12}$ The $5-\mathrm{HT}_{2 \mathrm{C}}$ has a close relation with obesity, animal studies conducted explains that $5-\mathrm{HT}_{2 \mathrm{C}}$ receptor lacking mice is slightly obese. Additionally, the receptor is located in the hypothalamus, the region responsible for regulating appetite and feeding. . $^{13,14}$ Therefore, understanding the structural aspects of the 5$\mathrm{HT}_{2 \mathrm{C}}$ is critical in designing agonist as well as antagonist. However, like all other GPCRs, 5- $\mathrm{HT}_{2 \mathrm{C}}$ is also very difficult to crystallize because of its low natural abundance, inherent structural flexibility and instability in detergent solution. So, drug discovery research targeting $5-\mathrm{HT}_{2 \mathrm{C}}$ is dependent on ligand based pharmacophore or homology model based knowledge.

Bovine rhodopsin X-ray crystal structure (pdb code 1F88), which belongs to the opsin subfamily of class A GPCR, was the mostly used template for homology modeling of all GPCRs. Recently another X-ray crystal structure of GPCR, beta 2 Adrenergic Receptor ( $\beta 2 \mathrm{AR}$, pdb code $2 \mathrm{RH} 1$ ), a member of amine subfamily has been solved. Cherezov et al. have crystallized this receptor by fusing T4 lysozyme fusion protein at $2.4 \AA$ resolution bound with partial inverse agonist carazolol. ${ }^{15}$ As this new X-ray crystal is a member of amine subfamily, there is a good chance that the generating homology model using this template represents clear idea about 5$\mathrm{HT}_{2 \mathrm{C}} \mathrm{R}$ and its binding interactions with ligand.

Previously, Amaury et al. ${ }^{16}$ modeled 5- $\mathrm{HT}_{2 \mathrm{C}} \mathrm{R}$ using bovine rhodopsin template in 2006. In this study, homology model of $5-\mathrm{HT}_{2 \mathrm{C}}$ receptor was built using $\beta 2 \mathrm{AR}$ crystal structure 
Table 1. Sequence identity and similarity between 5-HT2C receptor and the PDB templates reported by BLAST search

\begin{tabular}{cccccc}
\hline PDB code & Name & Resolution (A) & Identity (\%) & Similarity (\%) & Reference \\
\hline 2R4R & Human Beta2 Adrenoceptor & 3.40 & 32 & 50 & 40 \\
2RH1 $^{a}$ & Human Beta2 Adrenoceptor & 2.40 & 35 & 55 & 41 \\
1F88 & Bovine Rhodopsin & 2.80 & 20 & 37 & 42 \\
\hline
\end{tabular}

${ }^{a}$ The bold PDB template was used for homology modeling

template. Additionally, known agonists and antagonists have been docked to explore binding interaction inside the TM which also conforms the literature. The model utility has been demonstrated by our group to identify low-nM agonist molecules in conjunction with pharmacophore searching. ${ }^{17}$ Therefore this model is helpful to understand the ligand binding mechanism and receptor based virtual screen to identify novel lead molecules, which can have potential to treat depression and obesity.

\section{Experimental Methods}

Building Homology Model of 5-HT ${ }_{2 \mathrm{C}}$ R. In the absence of experimentally derived structure, homology modeling predicts the three-dimensional structure of a given protein sequence or target based primarily on its alignment to one or more related proteins of known structure or templates. ${ }^{18}$ The homologous search of 5- $\mathrm{HT}_{2 \mathrm{C}} \mathrm{R}$ (swissprot: P28335) was carried out by standard tool of sequence database searches, e.g., blastp (protein-protein BLAST). From BLASTP search results, 2RH1 was considered as template because it was crystallized in good resolution and had better identity and similarity with the target sequence compared to other pdb structures (Table 1).

Homology modeling part was done using inbuilt MODELER module of Discovery Studio (DS) (http://accelrys.com/) version 2.0. The X-ray crystal structure of beta 2 adrenergic receptor ( $\mathrm{pdb}$ code 2RH1) was obtained from the Protein Data Bank, ${ }^{19,20}$ it was crystallized by tagging T4 lysozyme fusion protein replacing third intracellular loop (ICL3). Prior to modeling the T4 lysozyme chimeric protein, ligands and water molecules were removed from the X-ray crystal structure. $5-\mathrm{HT}_{2 \mathrm{C}}$ receptors functional unit sequence was used in alignment with template by means of trimming the $\mathrm{N}$ - and C-terminal extra residues of target. The alignment was carried out by align2D module (Fig. 1) of DS program, MODELLER $^{21}$ incorporated in DS was used to model 5$\mathrm{HT}_{2 \mathrm{C}}$. Then the intracellular loops of the model was cut out, taken to Sybyl and minimized using Tripos force field. The minimized protein was then checked for its structural validation by analyzing Ramachandran plot using the program PROCHECK. ${ }^{22}$ This minimization mainly attributed to side chain optimization, therefore we have not consider the intracellular region. Moreover, beta 2 adrenergic receptor intracellular loops can show different orientation due to the induced fit effect according to the chimeric unit conformation.

Molecular Docking with Known Ligands. To explore binding interaction of ligand with the receptor four agonists, compound 1-4 (Fig. 2) and four antagonists, compound 5-8 (Fig. 3) with different scaffold and nanomolar $k_{i}$ value were

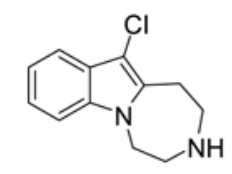

1 $\mathrm{ki}=4.7 \mathrm{nM}$<smiles>CC(N)Cn1ncc2ccc(O)c(F)c21</smiles>
3 $\mathrm{ki}=1 \mathrm{nM}$<smiles>O=C1Nc2cc(Cl)c(Cl)cc2N2CCNCC12</smiles>

2

$\mathrm{ki}=3 \mathrm{nM}$

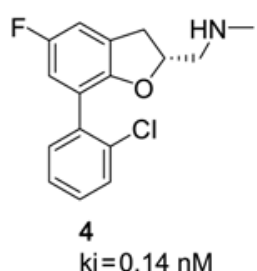

Figure 2. Agonists compounds (1-4) used for docking analysis.

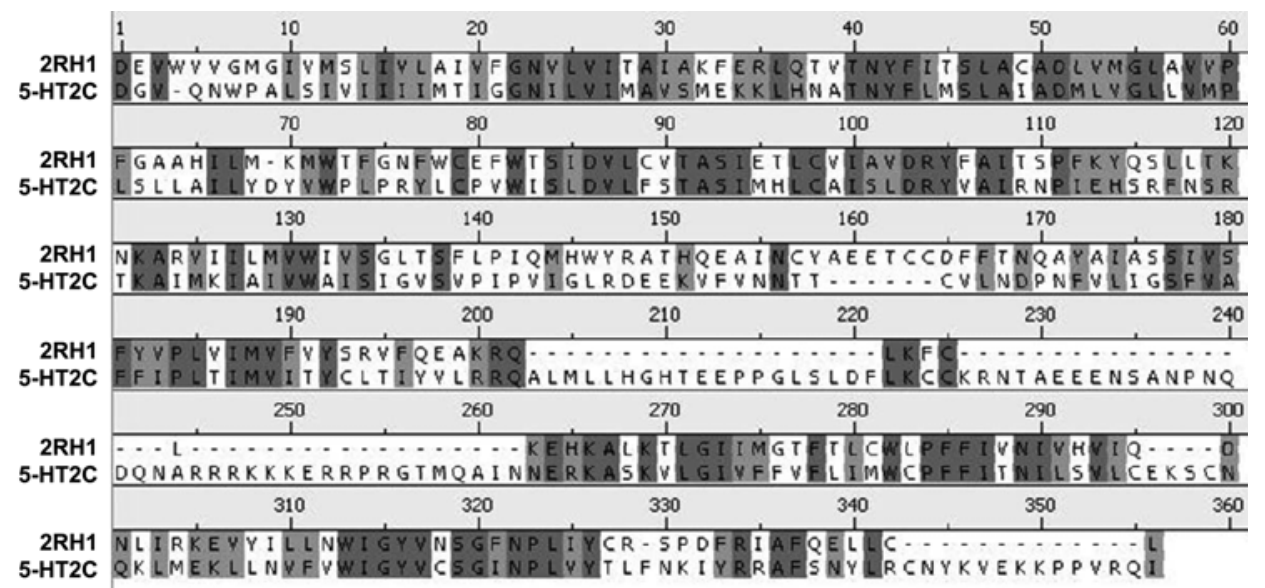

Figure 1. Alignment of $2 \mathrm{RH} 1$ and $5-\mathrm{HT}_{2 \mathrm{C}}$ sequences showing the identical (dark shaded) and closely related (light shaded) residues. 

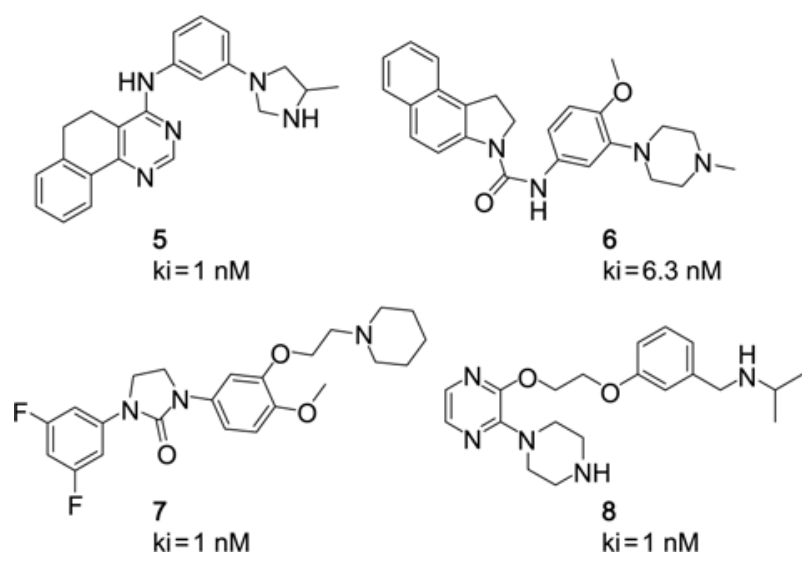

Figure 3. Antagonists compounds (5-8) used for docking analysis.

docked by Flex-X, ${ }^{23}$ while docking ligand molecules were kept flexible. Flex-X used physicochemical matching and fragment growing approach to conformation modeling of ligand molecules. Compound $\mathbf{1}$ is azepino indole derivative, which is $2 \mathrm{~A}$ and $2 \mathrm{C}$ specific ${ }^{24}$ agonist. Compound $\mathbf{2}$ is quinoxalinone compound with good activity over all 5-HT2 receptors. ${ }^{25}$ Compound $\mathbf{3}$ is aminopropyl indazole analogue with ocular hypotensive activity. ${ }^{26}$ Compound $\mathbf{4}$ is derivative of benzofuranyl alkanamines with antipsychotic functions. ${ }^{27}$ The diaryl derivative, compound $\mathbf{5}$ is specific $2 \mathrm{C}$ antagonist. ${ }^{28}$ Compound $\mathbf{6}$ is benzoindoline derivative with good antagonistic activity. ${ }^{29}$ Compound 7 is also a selective antagonist of bisaryl imidazolidin moiety. ${ }^{30}$ Compound $\mathbf{8}$ has been taken from Integrity, Prous Science having $3 \mathrm{nM}$ activity. ${ }^{31}$ In class A GPCR, agonists and antagonists are supposed to occupy same binding area inside the TM, thereby share some common amino acid residues in the binding site. Usually antagonists share amino acids either covering whole agonist binding sites or some of them. This property is known as umbrella effect of antagonist. ${ }^{32}$ According to various literatures Asp134 of TM3 is the most vital residues for ligand interaction. This residue and surrounding residues within $6.5 \AA$ were considered as possible active site during docking.

Sequence Analysis. All primary sequences of 5- $\mathrm{HT}_{2 \mathrm{~A}}, 5-$ $\mathrm{HT}_{2 \mathrm{~B}}, 5-\mathrm{HT}_{2 \mathrm{C}}$ and ADRB2 (Swiss-Prot entry P28223, P41595, $\mathrm{P} 28335$ and P07550, respectively) were collected from Swiss-Prot TrEMBL databases (http://www.expasy.ch/sprot/). Multiple sequence alignment was performed using the ClustalW2 program $^{33}$ for comparative analysis of all the sequences.

\section{Results}

Homology Model of 5-HT $\mathbf{2}_{\mathbf{C}} \mathbf{R}$. Since $5-\mathrm{HT}_{2 \mathrm{C}} \mathrm{R}$ ligands have different cellular effects and are related to many signal pathways, therefore, it is critical to understand the insight of agonist/antagonist binding to enhance drug discovery process. Both agonist and antagonist are believed to be binding in the same pocket however, subtle changes in binding patterns triggers various biological responses. As the $3 \mathrm{D}$ (a)

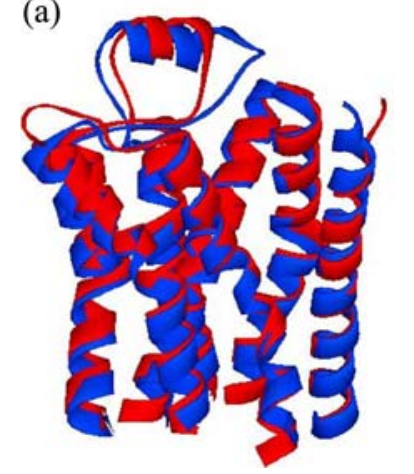

(b)

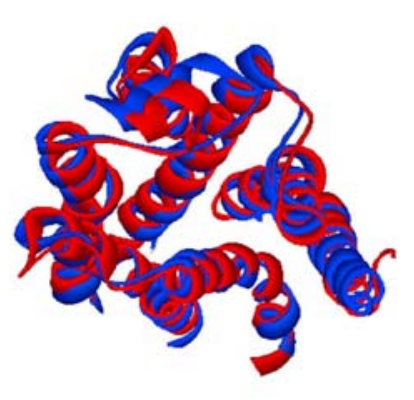

Figure 4. 3D superimposition of 5- $\mathrm{HT}_{2 \mathrm{C}}$ model (red) and template 2RH1 (blue) (a) side view (b) top view from extra cellular side.

structure of 5-HT $\mathrm{H}_{2 \mathrm{C}} \mathrm{R}$ is not yet available, homology modeled structure was developed (Fig. 4). Before, bovine rhodopsin was the widely used template to model this receptor, new X-ray crystal structure of $\beta 2 \mathrm{AR}$ opens various possibilities to understand the structure of 5-HT2C receptor structure. The generated model having lesser root mean square deviation (RMSD) of $2.039 \AA$ with template structure, additionally, Ramachandran plot analysis shows 89.2\% residues are in most favored and $9.1 \%$ are in additional allowed regions, whereas only $1.7 \%$ of residues in disallowed region.

Interaction of Agonist. Compound 1-4 has shown possible H-bonding interaction with Ile131, Asp134, Ser138 of TM3; Arg195 of ECL2 and Tyr358 of TM7. Diazepane ring NH of Compound 1 shows H-bonding with Asp134 and Tyr358; Asp134 acts as H-Bond acceptor and Tyr358 acts as both donor as well as acceptor. The indoline part makes good hydrophobic interaction with conserved hydrophobic residues Trp324, Phe327 and Phe328 of TM6 (Fig. 5a). Compound 2 shows three possible H-bonding interactions in the active site. Asp134 and Tyr358 interact with $\mathrm{NH}$ part of piperazine moiety and Ser138 make H-bonding with oxygen whereas the dichlorobenzene part contributes hydrophobic interaction (Fig. 5b). Compound 3 shows four possible H-bonding interactions with Asp134, Ser138, Arg195 and Tyr358. The amine part showed to interact with Asp134 and Tyr358, the indazole nitrogen made H-bonding with Arg195 and hydroxyl group interact with Ser138 (Fig. 5c). Compound 4 shows two H-bonding with Ile131 and Arg195, amine part interact with Ile131 and oxygen of benzofuran make H-bonding with Arg195. The chloro benzene part makes hydrophobic interaction with the hydrophobic residues (Fig. 5d).

Interaction of Antagonist. Compound 5-8 has shown Hbonding with Asp134 of TM3, Arg195, Val208 of ECL2, Asn351 and Tyr358 of TM7. Amine group linking tricyclic part with benzene of compound 5 makes H-bonding with Asp134, and nitrogen of quinazoline moiety with Arg195. The tricyclic part was headed to the hydrophobic cavity (Fig. 6a). Compound 6 has two possible H-bonding with Asp134 and Tyr358 by hydrogen of amide group. The benzoindole part makes strong hydrophobic interaction (Fig. 6b). Compound 7 has shown two H-bonding, one with Arg195 and 
(a)

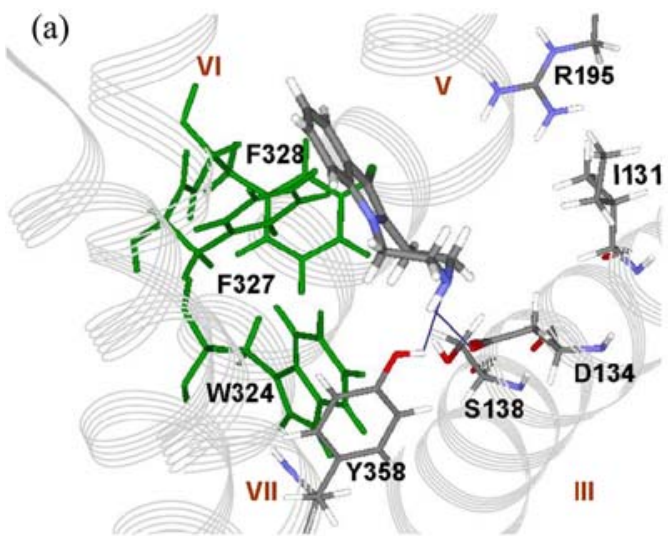

(c)
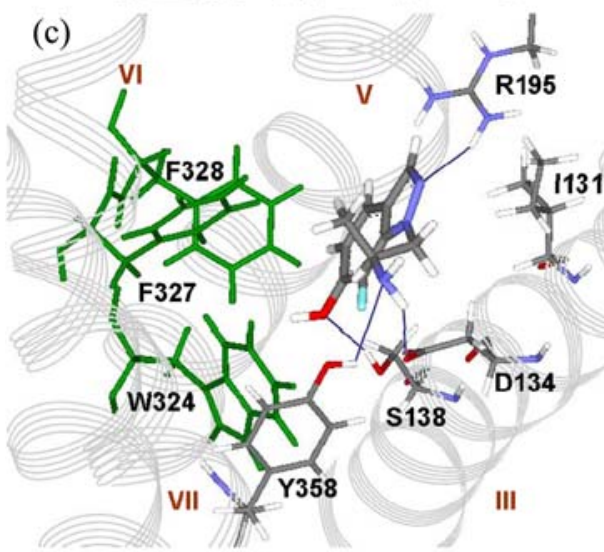

(b)

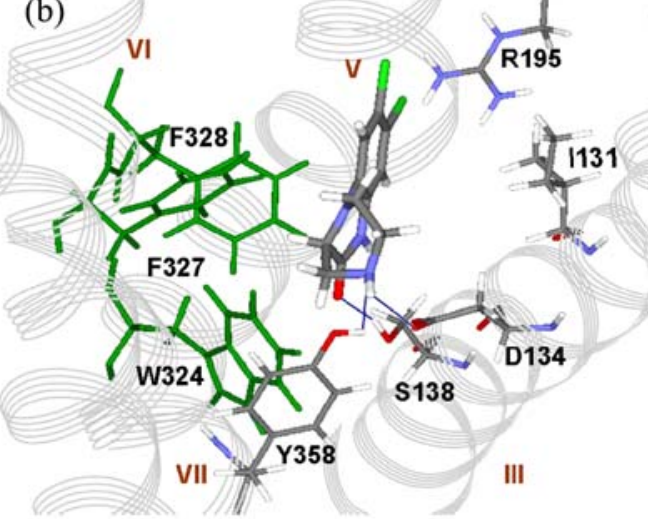

(d)

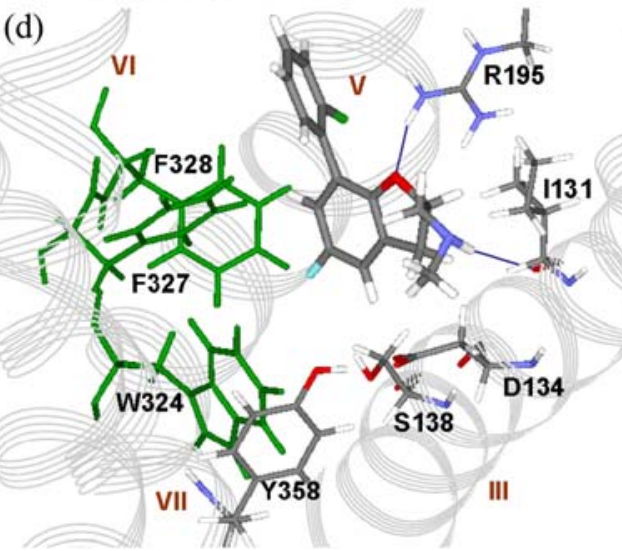

Figure 5. Plausible binding mode of agonists 1-4 (a-d) in the $5-\mathrm{HT}_{2 \mathrm{C}}$ model. The residues shown in green are highly conserved hydrophobic residues. Hydrogen bonding represented as in blue line.
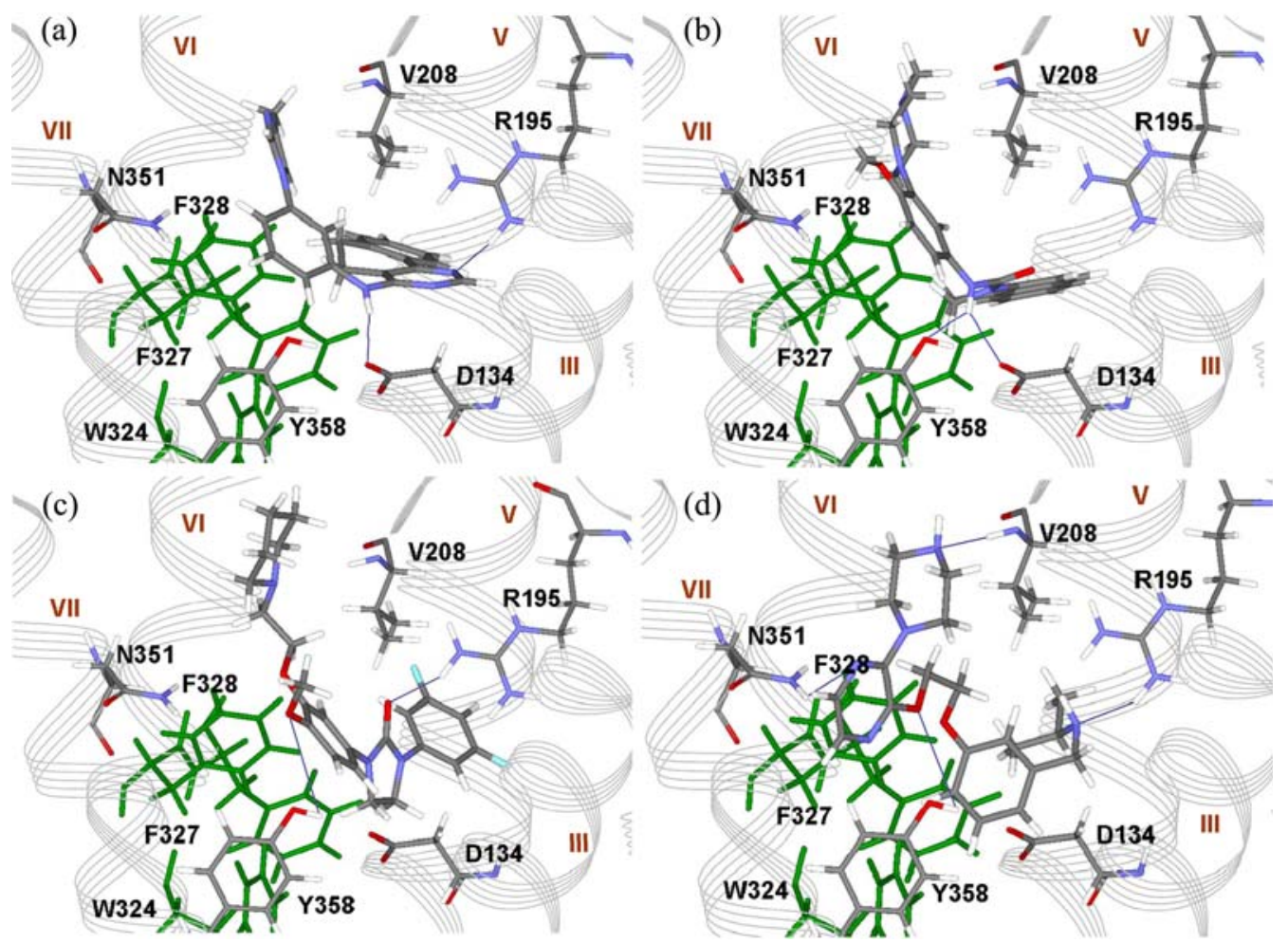

Figure 6. Plausible binding mode of antagonists 5-8 (a-d) in the 5- $\mathrm{HT}_{2 \mathrm{C}}$ model. The residues shown in green are highly conserved hydrophobic residues. Hydrogen bonding represented as in blue line. 


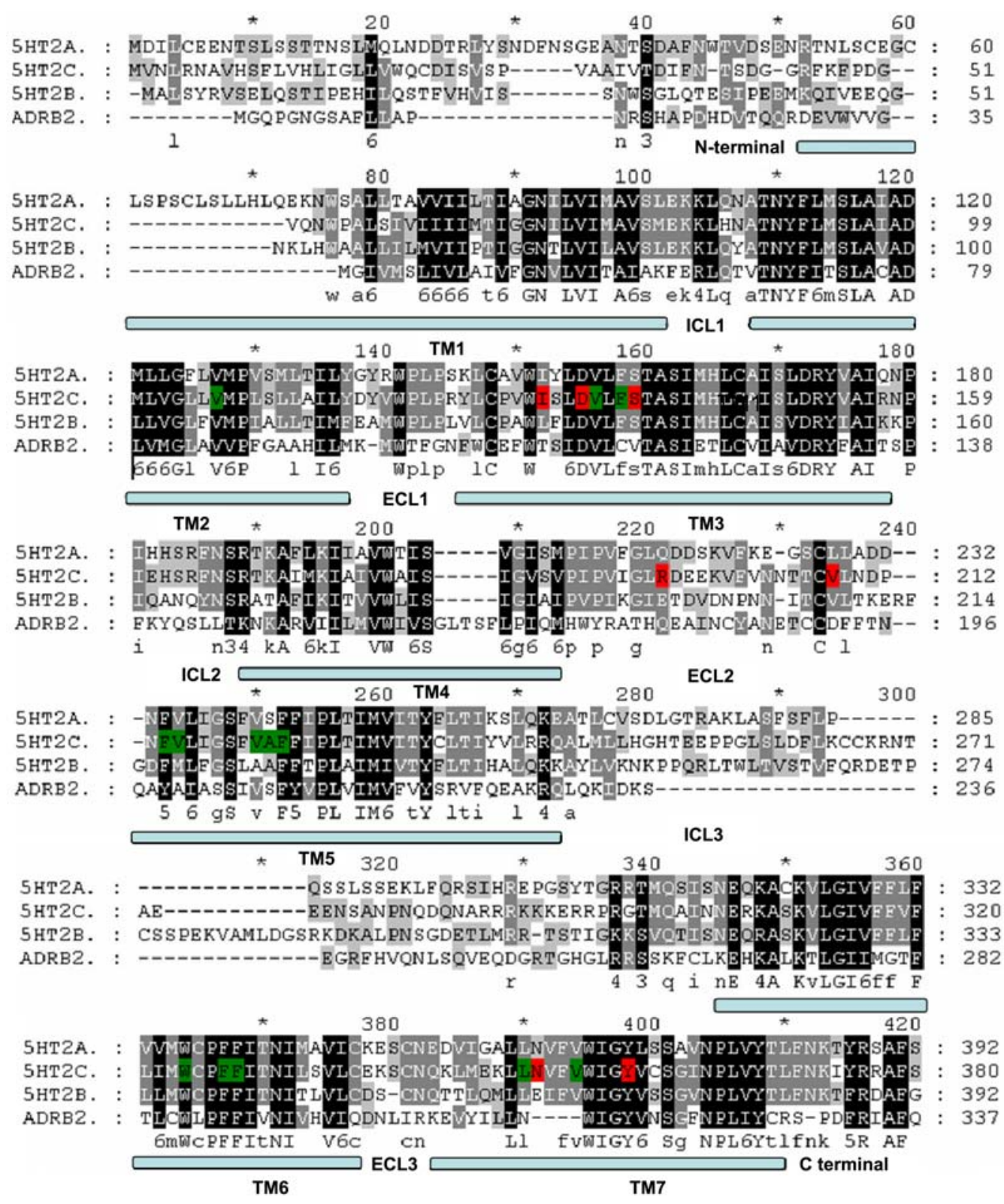

Figure 7. Multiple sequence alignment of $5-\mathrm{HT}_{2 \mathrm{~A}} \mathrm{R}, 5-\mathrm{HT}_{2 \mathrm{~B}} \mathrm{R}, 5-\mathrm{HT}_{2 \mathrm{C}} \mathrm{R}$ and $\mathrm{ADRB} 2$. In $5-\mathrm{HT}_{2 \mathrm{C}} \mathrm{R}$ red shaded residues are involved in possible H-bonding and the green shaded are hydrophobic residues within the $4 \AA$ of the ligands. The TMs, ICLs and ECLs of ADRB2 are shown under the alignment.

another with Tyr358. The imidazolidine part interacts with Arg195 and anisole oxygen interacts with Tyr358. The difluorophenyl imidazolidin make the hydrophobic interaction (Fig. 6c). Compound $\mathbf{8}$ has shown four H-bonding with Arg195, Val 208, Asn351 and Tyr358. The amine interacts with Arg195, the piperazine nitrogen with Val208, the pyrazine nitrogen with Asn351 and oxygen with Tyr358. The benzylpropanamine part makes hydrophobic interaction with three conserved hydrophobic residues (Fig. 6d).

Surrounding the ligands several hydrophobic residues have been observed which has at least one atom within $4 \AA$ range. These residues are Val106 of TM2, Val135, Phe137, Phe214, Val215, Val221, Ala222, Phe223, Trp324, Phe327, Phe328, Leu350 and Val354. Among these residues Trp324,
Phe327 and Phe328 are highly conserved in class A GPCR.

Sequence Analysis. Multiple Sequence analysis of 5$\mathrm{HT}_{2 \mathrm{~A}}, 5-\mathrm{HT}_{2 \mathrm{~B}}, 5-\mathrm{HT}_{2 \mathrm{C}}$ and ADRB2 was performed to identify the conserved and the unique residues among them and to correlate with the results of docking studies (Fig. 7). Ile131 is found in 5- $\mathrm{HT}_{2 \mathrm{~A}}$ and $5-\mathrm{HT}_{2 \mathrm{C}}$, which can possibly contribute to dual specificity. Ser138 is conserved in $5-\mathrm{HT}_{2}$, which is replaced by Valine in ADRB2. Arg195 is the residue hanging from ECL2 to make ligand contact and it has been observed that this residue is not conserved which emphasize its contribution for ligand specificity. Asp134 and Tyr358 are highly conserved among amine subfamily GPCRs. Val208 of ECL2 and Asn351 of TM7 might also contribute dual specificity to $5-\mathrm{HT}_{2}$ subtypes. 
(a)

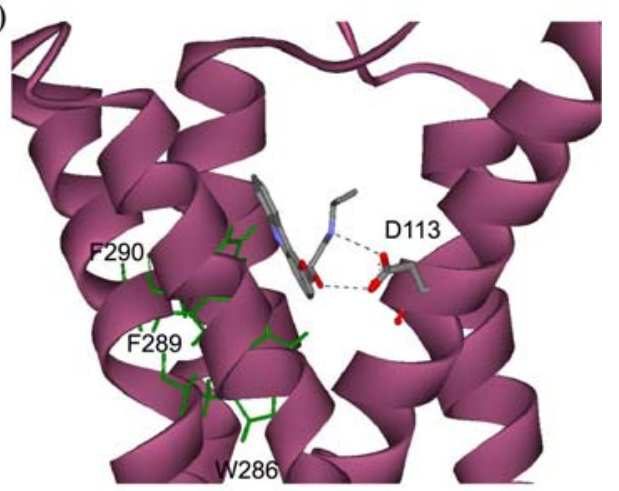

(b)

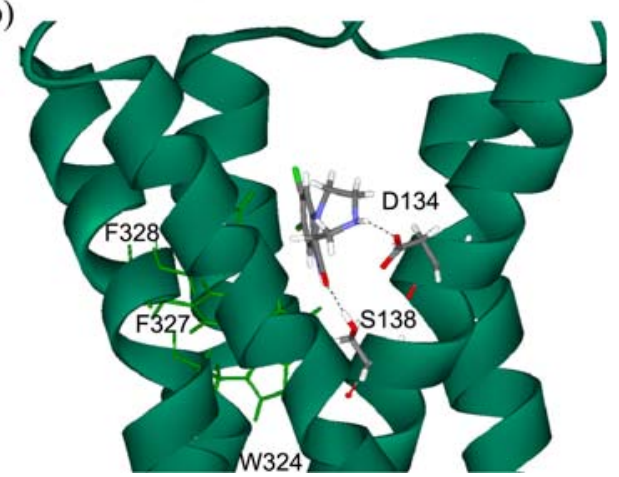

Figure 8. conformation comparison of experimentally derived 2RH1 bound carazolol (a) and docked conformation of compound 2 (b) with $5-\mathrm{HT}_{2 \mathrm{C}} \mathrm{R}$. These two compounds are having similar hydrophobic interaction (residues in green) and additionally hydrogen bond with aspartic acid.

\section{Discussions}

Several studies have shown that Asp134 and Ser138 in TM3 is vital for ligand binding in different GPCRs. Mutation of Asp134 to Ala has shown reduced binding affinity of $\left[{ }^{3} \mathrm{H}\right]$ mesulrgine and sarpogrelate. ${ }^{34}$ Site directed mutagenesis analysis of Asp155 of 5- $\mathrm{HT}_{2 \mathrm{~A}}$ receptor (Asp134 in 5- $\mathrm{HT}_{2 \mathrm{C}}$ receptor) to Asn has shown six fold decreased binding with natural ligand serotonin. ${ }^{35}$ They also speculated the probable interaction of Asp155 with amine group of the ligand, which is also explained by our docking studies. Docking study of agomelatine in 5- $\mathrm{HT}_{2 \mathrm{C}}$ receptor has also proposed Asp134 as important ligand binding residue. ${ }^{16}$ Herrik-Davis et al. has shown that mutation of Ser138 of TM3 to Arg reduces the ligand binding affinity and is responsible for providing active conformation to the receptor. ${ }^{36}$

Different hydrophobic amino acids around the ligands have been reported for ligand binding and receptor activation by mutagenesis and molecular modeling studies. Mutation studies with 5-HT $2 \mathrm{~A}$ receptor has shown Phe340 and Tyr370 (Phe328 and Tyr358 in $5-\mathrm{HT}_{2 \mathrm{C}} \mathrm{R}$ respectively) has dramatic effect on ligand binding and efficacy. ${ }^{37}$ Choudhary et al. mentioned that Phe339 and Phe340 (Phe327 and Phe328 in $5-\mathrm{HT}_{2 \mathrm{C}}$ receptor) having effect on binding of 5-HT, DOI and few other ligands. ${ }^{38}$ Homology modeling study with rhodopsin has shown Trp324, Phe327 and Phe328 residues make hydrophobic box near the ligand ${ }^{39}$ which is in good agree- ment with our model.

For further validation of the model, binding mode of partial inverse agonist carazolol in $\beta 2 \mathrm{AR}$ crystal structure is compared with one of the docked ligand (Compound 2) in 5$\mathrm{HT}_{2 \mathrm{C}}$ receptor. It occupies the same space inside TM like carazolol, with an additional H-bonding with Ser138 of TM3. The carbazole moiety of carazolol is faced toward the three hydrophobic residues in TM6, similarly the quinoxaline moiety of compound 2 also having same $3 \mathrm{D}$ positioning inside 5- $\mathrm{HT}_{2 \mathrm{C}}$ receptor (Fig. 8). Besides, there are few shifts in the TM and ECLs of $\beta 2 A R$ compared to rhodopsin crystal structure. The TM3 of $\beta 2 \mathrm{AR}$ is almost $4 \AA$ displaced out of the binding pocket and TM5 is little close to the core. There is a major difference in ECL2, bovine rhodopsin has loop with two beta sheet which almost occupy the entrance of the TM cavity, whereas the $\beta 2 \mathrm{AR}$ contains short alpha helix in this loop. In $\beta 2 A R$ the short helix of ECL2 is pulled out of the TM cavity to allow ligands into the binding pocket and also providing sufficient space for structurally big ligands. ${ }^{15}$ They also concluded that the conserved residues provide common core in class A GPCR, whereas variable portions confer large spectrum of ligand binding capability. These differences of $\beta 2 \mathrm{AR}$ turns it as better template and enhances the chance of getting more accurate and realistic model of class A amine subfamily.

In general $5-\mathrm{HT}_{2 \mathrm{C}}$, agonist compounds are small and have limited interaction compare to antagonist compounds. Agonist and antagonist frequently forming hydrogen bond with Asp134, Tyr358, Arg195, this could be an umbrella effect. However, from the activity comparison we can propose that agonistic activity increase if compound interacts with Ile 131 or Ser 138 along with the common hydrogen bond and conserved hydrophobic interaction. Antagonist compounds establishing hydrogen bond with Arg 195 are having higher activity, such as compound 5, 7 and 8. Additionaly, Val 28 and Asn 351 are interacting only with antagonist molecules. Compound 6 is not having high antagonistic effect $(\mathrm{Ki}=$ $6 \mathrm{nM})$ as this compound is not forming polar interaction with additional residues other than Asp134 and Tyr358, which are common residue to agonist compounds as well. From the structural aspect we can conclude that antagonist molecules are bigger, therefore can have an interaction with key residues and additionally approach nearby residues in the active site to carryout antagonistic effect.

\section{Conclusion}

In this study homology model of $5-\mathrm{HT}_{2 \mathrm{C}}$ receptor has been built, minimized and validated using newly crystallized class A GPCR $\beta 2 \mathrm{AR}$ as template. Both the $5-\mathrm{HT}_{2 \mathrm{C}}$ receptor and $\beta 2 \mathrm{AR}$ belongs to the class A amine group of GPCR, therefore amine group structure can be a optimal template to model $5-\mathrm{HT}_{2 \mathrm{C}}$ than opsin group rhodopsin. Present model build on $\beta 2 \mathrm{AR}$ having higher possibility of representing closer and accurate 5- $\mathrm{HT}_{2 \mathrm{C}}$ structure. Furthermore, docking study of known active agonists and antagonists of different scaffolds explore the putative binding modes. The docking 
simulation conducted helps in identifying key residues forming hydrogen and hydrophobic interaction with agonist and antagonist molecules, this information can be effectively used in drug designing to discover novel lead molecules.

Acknowledgments. This work is supported by Korea Institute of Science and Technology.

\section{References}

1. Fredriksson, R.; Lagerstrom, M. C.; Lundin, L. G.; Schioth, H. B. Mol. Pharmacol. 2003, 63, 1256.

2. Takeda, S.; Kadowaki, S.; Haga, T.; Takaesu, H.; Mitaku, S. Febs. Letters 2002, 520, 97.

3. Tierney, A. J. Comp. Biochem. Phys. A 2001, 128, 791.

4. Hoyer, D.; Hannon, J. P.; Martin, G. R. Pharmacol. Biochem. Be. 2002, 71, 533.

5. Hoyer, D.; Clarke, D. E.; Fozard, J. R.; Hartig, P. R.; Martin, G. R.; Mylecharane, E. J.; Saxena, P. R.; Humphrey, P. P. A. Pharmacological Reviews 1994, 46, 157

6. Burns, C. M.; Chu, H.; Rueter, S. M.; Hutchinson, L. K.; Canton, H.; SandersBush, E.; Emeson, R. B. Nature 1997, 387, 303.

7. Leysen, J. E. Curr. Drug Targets CNS Neurol. Disord. 2004, 3, 11.

8. Roth, B. L.; Willins, D. L.; Kristiansen, K.; Kroeze, W. K. Pharmacol. Therapeut. 1998, 79, 231.

9. Pranzatelli, M. R.; Murthy, J. N.; Pluchino, R. S. J. Pharmacol. Exp. Ther. 1992, 261, 161.

10. Abramowski, D.; Staufenbiel, M. J. Neurochem. 1995, 65, 782.

11. Becamel, C.; Alonso, G.; Geleotti, N.; Demey, E.; Jouin, P.; Ullmer, C.; Dumuis, A.; Bockaert, J.; Marin, P. Embo. J. 2002, 21, 2332.

12. Niswender, C. M.; Copeland, S. C.; Herrick-Davis, K.; Emeson, R. B.; Sanders-Bush, E. J. Biol. Chem. 1999, 274, 9472.

13. Bickerdike, M. J. Current Topics in Medicinal Chemistry 2003, 3, 885.

14. Smith, B. M.; Thomsen, W. J.; Grottick, A. J. Expert. Opinion on Investigational Drugs 2006, 15, 257.

15. Cherezov, V.; Rosenbaum, D. M.; Hanson, M. A.; Rasmussen, S. G. F.; Thian, F. S.; Kobilka, T. S.; Choi, H. J.; Kuhn, P.; Weis, W. I.; Kobilka, B. K.; Stevens, R. C. Science 2007, 318, 1258.

16. Farce, A.; Dilly, S.; Yous, S.; Berthelot, P.; Chavatte, P. J. Enzym. Inhib. Med. Ch. 2006, 21, 285.

17. Ahmed, A.; Choo, H.; Cho, Y. S.; Park, W. K.; Pae, A. N. Bioorganic \& Medicinal Chemistry 2009, 17, 4559.

18. Marti-Renom, M. A.; Stuart, A. C.; Fiser, A.; Sanchez, R.; Melo, F.; Sali, A. Annu. Rev. Bioph. Biom. 2000, 29, 291.

19. Berman, H.; Henrick, K.; Nakamura, H.; Markley, J. L. Nucleic. Acids Research 2007, 35, D301.

20. Berman, H. M.; Westbrook, J.; Feng, Z.; Gilliland, G.; Bhat, T. N.; Weissig, H.; Shindyalov, I. N.; Bourne, P. E. Nucleic. Acids Research 2000, 28, 235

21. Sali, A.; Blundell, T. L. Journal of Molecular Biology 1993, 234, 779.
22. Laskowski, R. A.; Macarthur, M. W.; Moss, D. S.; Thornton, J. M. J. Appl. Crystallogr. 1993, 26, 283.

23. Rarey, M.; Kramer, B.; Lengauer, T.; Klebe, G. Journal of Molecular Biology 1996, 261, 470.

24. Ennis, M. D.; Hoffman, R. L.; Ghazal, N. B.; Olson, R. M.; Knauer, C. S.; Chio, C. L.; Hyslop, D. K.; Campbell, J. E.; Fitzgerald, L. W.; Nichols, N. F.; Svensson, K. A.; McCall, R. B.; Haber, C. L.; Kagey, M. L.; Dinh, D. M. Bioorg. Med. Chem. Lett. 2003, 13, 2369 .

25. Welmaker, G. S.; Nelson, J. A.; Sabalski, J. E.; Sabb, A. L.; Potoski, J. R.; Graziano, D.; Kagan, M.; Coupet, J.; Dunlop, J.; Mazandarani, H.; Rosenzweig-Lipson, S.; Sukoff, S.; Zhang, Y. X. Bioorg. Med. Chem. Lett. 2000, 10, 1991.

26. May, J. A.; Dantanarayana, A. P.; Zinke, P. W.; McLaughlin, M. A.; Sharif, N. A. J. Med. Chem. 2006, 49, 318.

27. Gross, J. L.; Williams, M. J.; Stack, G. P.; Gao, H.; Zhou, D. USA Patent, $W O / 2006 / 1161512005$.

28. Harada, K.; Aota, M.; Inoue, T.; Matsuda, R.; Mihara, T.; Yamaji, T.; Ishibashi, K.; Matsuoka, N. Eur. J. Pharmacol 2006, 553, 171.

29. Lavielle, G.; Muller, O.; Millan, M.; Gobert, A.; Di Cara, B. US Patent 69984032006

30. Goodacre, C. J.; Bromidge, S. M.; Clapham, D.; King, F. D.; Lovell, P. J.; Allen, M.; Campbell, L. P.; Holland, V.; Riley, G. J.; Starr, K. R.; Trail, B. K.; Wood, M. D. Bioorg. Med. Chem. Lett. 2005, 15 , 4989.

31. Prous. Drug Data Report 2002, 24, 761.

32. Patrick, G. L. An Introduction to Medicinal Chemistry; Oxford University Press: New York, 2005.

33. Thompson, J. D.; Higgins, D. G.; Gibson, T. J. Nucleic Acids Research 1994, 22, 4673.

34. Muntasir, H. A.; Takahashi, J.; Rashid, M.; Ahmed, M.; Komiyama, T.; Hossain, M.; Kawakami, J.; Nashimoto, M.; Nagatomo, T. Biol. Pharm. Bull. 2006, 29, 1645.

35. Wang, C. D.; Gallaher, T. K.; Shih, J. C. Mol. Pharmacol 1993, $43,931$.

36. Herrick-Davis, K.; Grinde, E.; Harrigan, T. J.; Mazurkiewicz, J. E. J. Biol. Chem. 2005, 280, 40144.

37. Roth, B. L.; Shoham, M.; Choudhary, M. S.; Khan, N. Mol. Pharmacol 1997, 52, 259.

38. Choudhary, M. S.; Craigo, S.; Roth, B. L. Mol. Pharmacol 1993, 43,755 .

39. Rashid, M.; Manivet, P.; Nishio, H.; Pratuangdejkul, J.; Rajab, M.; Ishiguro, M.; Launay, J. M.; Nagatomo, T. Life Sciences 2003, 73, 193.

40. Rasmussen, S. G. F.; Choi, H. J.; Rosenbaum, D. M.; Kobilka, T. S.; Thian, F. S.; Edwards, P. C.; Burghammer, M.; Ratnala, V. R. P.; Sanishvili, R.; Fischetti, R. F.; Schertler, G. F. X.; Weis, W. I.; Kobilka, B. K. Nature 2007, 450, 383

41. Rosenbaum, D. M.; Cherezov, V.; Hanson, M. A.; Rasmussen, S. G. F.; Thian, F. S.; Kobilka, T. S.; Choi, H. J.; Yao, X. J.; Weis, W. I.; Stevens, R. C.; Kobilka, B. K. Science 2007, 318, 1266.

42. Palczewski, K.; Kumasaka, T.; Hori, T.; Behnke, C. A.; Motoshima, H.; Fox, B. A.; Le Trong, I.; Teller, D. C.; Okada, T.; Stenkamp, R. E.; Yamamoto, M.; Miyano, M. Science 2000, 289, 739. 